\title{
Aesthetic Elements of Ceramic Art Design
}

\author{
Mingyu Liu \\ School of Art and Museology \\ Jingdezhen Ceramic Institute \\ Jingdezhen, Jiangxi, China
}

\begin{abstract}
Aesthetic value, apart from practical value, needs to be taken into account in ceramic art design. Being a combination of rationality and sensibility, the principles of aesthetic activity in ceramic art design include both emotional and rational elements. The emotional elements of aesthetics in ceramic art design mainly include formal beauty and artistic beauty. And the rational elements include functional beauty and technical beauty.
\end{abstract}

Keywords-formal beauty; artistic beauty; functional beauty; technical beauty

\section{INTRODUCTION}

Unlike pure ceramic art creation, being a branch of industrial design, ceramic art design is a ceramic-based craft of creation. The application value of modern ceramic art design includes not only utility function, but also spiritual function. Aesthetic issue has become a core issue drawing attention of designers, as it is the main carrier of spiritual function of a ceramic product.

Rather than simply considering the effect of color, formality or texture, the aesthetic of ceramic art design concerns overall consideration of design elements that can trigger emotions and bring enjoyment on a macroscopic standpoint. As an activating combining rationality and sensibility, aesthetic principles of ceramic art design contain both sensible elements like formal beauty and artistic beauty, and rational elements like functional beauty and technical beauty.

\section{The SEnsible Aesthetic Elements of Ceramic ART DESIGN}

Li Zehou, a renowned scholar, once explained the meaning of beauty from an etymologic perspective. Based on the theory, the Chinese character for beauty is consist of the characters of sheep and big, denoting that a sheep is believed to be beautiful if it is fat and big, which illustrates that aesthetics and sensibility coexist, both related to the satisfaction of human's needs and sensory pleasure. The nature of formal beauty and artistic beauty of ceramic art design is established upon subjective intuition, which is for sensual pleasure that is beyond utility. In this sense, formal beauty and artistic beauty of ceramic art design belongs to the domain of sensible aesthetic element.

\section{A. Formal Beauty}

During the process of social practice, natural attributes of materials like color, figure and shape are combined by certain rules, creating products or objects with unique beauty of form. Therefore, form beauty is an aesthetics character composed of sensual materials like color, figure and shape, and their arrangement in accordance with combination rules, such as unity, cadence and rhythm.

Formal beauty of ceramic art design, on one hand, includes aesthetic feature of sensual materials, i.e. the natural attributes of materials that form a product, like color, figure and shape, on the other hand, includes the aesthetic feature of the combination rules of the sensual materials. Specifically, the color of a ceramic product includes the color of glaze and the original color of the ceramic. The figure of a ceramic product includes lines and curves. And the shape of a ceramic product can be regular and irregular or hard line and soft line type. The above mentioned sensual materials, as the objective existence of nature, create aesthetic pleasure in observers by bringing material incentives to them through audio-visual senses. The combination rules of ceramic products' sensual materials, also called laws of formal beauty, mainly include cadence and rhythm, symmetry and equilibrium, contrast and unity. All of which deriving from the abstract generalization and summarization of regular patterns of a variety of beauty in the creation process, brings about different psychology impression and aesthetic experience.

\section{B. Artistic Beauty}

Artistic beauty, a unity of image and emotion, mainly includes objective image and subjective emotion. The artistic beauty of ceramic art design is embodied in the form of a product, and illustrated by the atmosphere created by the product decoration as well.

It is by the color of glaze, figures and shape that fulfills the visual presentation of a ceramic product. A combination of different colors, figures and shapes by the rules creating unique looks and various impressions, possesses power of delighting the people, while it appeals to the senses. The visual presentation of a ceramic product carries not only the functions, but also the aesthetic spirit and affection of the designers, playing a great role in the artistic beauty of a ceramic product.

Ceramic product decoration mainly includes adornment of pictures, colored glaze and textures. By pictures decorating, some patterns are added to the product, using techniques of 
applique, spray printing, printing, brushing, carving, incising, scraping and painting. By colored glaze decorating, the designers apply, pour, infiltrate, spray or sieve the glaze directly to the ceramics to create certain artistic effects. The glazes commonly used are monochrome glaze, transmutation glaze, blossom glaze, crystalline glaze, crackle glaze and so on Texture decoration includes two aspects: one is by exploiting the beauty of its original textures, relating to the surface structure, configuration and grain of the ceramics; the other is by creating artificial textures, demonstrating various visual effects in patterns, colors and density. Both of which have aesthetics characteristics of dynamics, vitality and naturality. Decoration upgrades ceramic products in their artistic value and marketing value, offering aesthetic pleasure to people, forming the main content of the artistic beauty in ceramic products.

\section{The Rational Aesthetic ElEMENTS OF CERAMIC ART DESIGN}

According to Li Zehou's theory, the second meaning of beauty from the perspective of etymology, the Chinese character for beauty can also be regarded as a combination of characters of people and sheep, implying that the scene of a people dancing wearing a sheepshead for decoration in a primitive witch ceremony activity, is considered to be beautiful. In this sense, beauty is associated with goodness, having a certain rational and social significance. The definition of goodness, at the material level, means utility value, and refers to moral value at the spiritual level, which means, when integrated with goodness, beauty becomes pleasant experience with rational meanings. The aesthetics beauty inheres in functional beauty and technical beauty in ceramic art design is for purpose of objective utility, material practicality and social efficiency, appealing to a person's social demands.

\section{A. Functional Beauty}

Beauty of function, i.e. the practical functions, the core aesthetical thought of ceramic art design, reflecting the relationship between beauty and good in material production, is the dialectical union between utilitarian and super-utilitarian aesthetics experiences. Function of a ceramic product is realized only in use. The convenience and usefulness of the product satisfies a person in spirit and emotion, inducing a sense of functional beauty, thus illustrating its existence.

Functional beauty of ceramic art design lies not in the function itself, but in the unity of its function and form. A ceramic product's function is not tangible, and must take products as a carrier. There is no function or functional beauty without the existence of the objective existence of a product. However, the function and form are constituent of functional beauty, between them the relations are not simply added together, but combined in an optimum way. Therefore, only the ceramic product with good functions and a form fairly matching with and fully embodying its functions can be evaluated as possessed with functional beauty.

\section{B. Technical Beauty}

Techniques are the experience, knowledge, methods, skills and expertise seen from the process of using and remaking the nature. And Technical beauty refers to the beauty in the field mentioned above. As ceramic art in nature is the embodiment of combination of techniques and art, people tend to appreciate it from a comprehensive perspective of processing technology, material and latent effectiveness, other than an artistry perspective only.

Technical beauty in configuration includes beauty of technical method and technical product. The technical methods mainly include techniques of performing, glazing, decorating and kilning, which can evoke the viewers' response of the aesthetic emotion like surprising, delighting and satisfying. The technical product is the ceramic product itself, which results from implementing techniques with unity of purpose and rules. Technical beauty mostly delivers through the beauty of the product.

Ceramic art design is essentially a combination of techniques and art. As techniques mainly deal with issues related with practical functions, technical beauty in ceramic art design is associated with functions. Technical beauty can come into view given the function of a ceramic product is achieved. If the visual effect of a ceramic product is superseded with its functions, technical beauty shall not present either. Therefore, the unity of techniques and forms is the most essential characteristic of technical beauty.

\section{CONCLUSION}

The aesthetic value of ceramic art design is consisting of formal beauty, artistic beauty, functional beauty and technical beauty. It requires us to give a rational grasp of these elements to cope better with aesthetic appreciation or creation of ceramic products.

\section{REFERENCES}

[1] Li Yanzu, Wang Mingzhi, Xu Hengchun,Aesthetics in Design, Beijing: Tsinghua University Press, 2006.7.

[2] Li Zehou, Three Letters on Aesthetics, Hefei: Anhui Literature and Art Publishing House, 1999.

[3] Li Chaode, Aesthetics in Design, Hefei:Anhui Art Publishing House, 2004.

[4] Li Zhengan, Ceramic Design, Hangzhou: Chinese Academy of Fine Arts Press, 2004.8.

[5] Zhang Chengzhong, Lv Ping, Design Psychology, Beijing: Peking University Press, 2007.2.

[6] Yu Jianrong, Zhang Chaohui, on aesthetic characteristics of ceramic products design, China Ceramics, Feb. 2005, Vol.41, No.1.

[7] Li Yanzu, on the "three elements" in design aesthetics, Journal of Huanghe S\&T University, Vol.5, No.1. 